\title{
Narrativa e memória na Amazônia de Dalcídio Jurandir
}

\author{
Paulo Jorge Nunes \\ Maíra Oliveira Maia ${ }^{\dagger}$ \\ Thainá Oliveira Chemelo
}

Dalcídio Ramos Jurandir nasceu em 1909, em Ponta de Pedras, então pequena vila localizada na Ilha do Marajó, no interior do Pará. Em 1910 se mudou com a família para Cachoeira do Arari, vila também marajoara, onde passou a infância. Em 1922, com 13 anos, mudou-se para Belém, quando então estudou no Grupo Barão do Rio Branco, concluindo, em 1924, o primário. Jurandir, em 1927, ingressou no então Ginásio Paes de Carvalho; ele, no entanto, não chega sequer a frequentar o terceiro ano. ${ }^{1}$

Em 1928 resolveu tentar a sorte na capital federal, o Rio de Janeiro, porém, não tendo como se sustentar, retorna a Belém. Seu amigo, Dr. Rainero Maroja, Intendente Municipal de Gurupá - Baixo Amazonas - nomeou Dalcídio Jurandir "secretário do Tesouro", em outubro de 1929. Nesse período, ele começa a escrever a primeira versão de seu romance, Chove nos campos de Cachoeira, o primeiro do ciclo que o próprio autor denominou "Ciclo do Extremo Norte". Em 1931, por indicação de amigos, é nomeado auxiliar de gabinete da interventoria do Estado, além de tornar-se colaborador dos jornais O Imparcial, Crítica e Estado do Pará.

Em 1935, em plena vigência da Academia do Peixe Frito, ${ }^{2}$ já participava ativamente da vida intelectual da cidade de Belém, escrevendo para as revistas Guaja-

Doutor em Letras e Literatura em Línguas Portuguesas e professor da Universidade da Amazônia (UNAMA), Belém, PA, Brasil. E-mail: pontedogalo3@gmail.com.

$\dagger$ Doutora em História e professora da Universidade da Amazônia (UNAMA), Belém, PA, Brasil. Email:mairamaia1309@yahoo.com.

¥ Mestranda no Programa de Pós-Graduação em Comunicação, Linguagem e Cultura na Universidade da Amazônia (UNAMA), Belém, PA, Brasil. E-mail: thainachemelo@hotmail.com.

1 Para conhecer Dalcídio Jurandir, ler Nunes; Pereira; Pereira, Dalcídio furandir - Romancista da Amazônia (literatura \& memória). Belém: Secult, 2006.

2 A Academia do Peixe Frito, associação lúdico-anárquica, de atuação em Belém, era composta por cerca de 13 rapazes, liderados por Bruno de Menezes (1896/1963); jornalistas e literatos, eles tinham consciência de que havia lacunas sociais e culturais que precisavam ser contempladas, uma juventude negra e de periferia não dispunha, grosso modo, recursos materiais para frequentar os cafés chiques da cidade (coisa que ocorria desde a década anterior). E isto remetia à ação de grupo que enfatizava inovações estéticas, defesa da Negritude e da Indianidade (NunEs; Torres, 2018). 
rina, A Semana e Pará Ilustrado, além de manter amizade com vários intelectuais e jornalistas.

Casou-se com Guiomarina Luzia Freire, em 1935. Nos anos de 1930, Dalcídio Jurandir já expressava ideias de esquerda e participou do apoio aos presos políticos que se envolveram no movimento liderado por Luís Carlos Prestes e a Aliança Nacional Libertadora, acarretando em sua prisão em Belém, no ano de 1936. Ficou encarcerado durante dois meses. Em 1937 é novamente preso por mais três meses devido à sua filiação ao Partido Comunista e a seu engajamento na campanha contra o fascismo.

Após esse período de maior perseguição política, reassume as suas funções na Diretoria Geral de Educação e Ensino, em Belém, e intensifica as suas atividades jornalísticas. Em 1939 transfere-se para Oeiras, na ilha do Marajó, onde passa a exercer o cargo de inspetor escolar; no entanto, não interrompe a sua colaboração com as revistas e jornais de Belém. Ao mesmo tempo, exigente no aprimoramento de sua criação literária, Dalcídio prossegue na escritura do já citado Chove nos campos de Cachoeira e Missuga, que depois viria a ser denominado Marajó. Em 1940, é convidado a trabalhar no recenseamento em Santarém, na região do Baixo Amazonas paraense. É de conhecimento público, devido a inúmeros compromissos profissionais, as dificuldades enfrentadas para a conclusão dos dois romances. Assim ele inscreve Chove nos campos de Cachoeira no concurso "Vecchi/Dom Casmurro" no Rio de Janeiro. Sem que ele saiba, seus amigos fazem a inscrição de Missunga, no mesmo certame; ele é premiado em primeiro lugar com Chove nos campos de Cachoeira enquanto Missunga é laureado com o terceiro lugar. Essa dupla vitória de Dalcídio Jurandir no concurso leva à sua transferência, em 1941, para o Rio de Janeiro. Na capital federal, militando no Partido Comunista e exercendo o jornalismo nos periódicos de esquerda, ele escreve os seus próximos romances, como o analisado neste estudo, Belém do Grão-Pará.

A experiência ordinária que define a prática da escrita e o projeto estético e político da literatura de Jurandir, torna o estudo de seus romances fundamentais para que hoje se possa compreender a sociedade paraense da primeira metade do século XX. O autor testemunhou este mundo e construiu nos seus romances uma interpretação política da sua experiência testemunhal, vista a partir das margens, em experiência apreendida, em primeiro momento, na Academia do Peixe Frito, de que ele foi participante esporádico mas decisivo, e, em segundo, na militância ativa do Partido Comunista. É justamente esta interpretação política e testemunhal que se irá problematizar neste presente estudo. Em nosso caso específico, estamos a tratar do Norte do Brasil, a 'Amazônia de Dalcídio', representada no romance que ora interpretamos.

Se, como ensinaram Williams e os ingleses ao renovarem o marxismo, o que valida a função social da cultura ordinária é a experiência pessoal, experiência esta como algo comum a toda a sociedade, então Jurandir, um homem do interior da Amazônia, comum, transformou a experiência ordinária de sua vida cotidiana 
material em dez romances, que compõem o Ciclo do Extremo Norte: Chove nos campos de Cachoeira (1941), Marajó (1947), Três casas e um rio (1958), Belém do Grão-Pará (1960), Passagem dos Inocentes (1963), Primeira Manhã (1967), Ponte do Galo (1971), Chão de Lobos (1976), Os habitantes (1976) e Ribanceira (1978). Além dos seus poemas póstumos e do romance sobre o extremo sul, Linha do Parque (1959), alguns destes romances - como Chove nos campos de Cachoeira e Belém do GrãoPará-, receberam prêmios nacionais importantes. Belém do Grão-Pará teve duas edições em Portugal, pela editora Europa-América.

Uma espécie de autor etnógrafo, ${ }^{3}$ Dalcídio Jurandir, intelectual atuante, deixa claro em depoimentos, entrevistas e cartas, que a sua perspectiva é prioritariamente a de romancista, embora também chame a atenção a sua prática jornalística, que faz par com a outra, a de criador de romances. Porém, devemos ressaltar que ele utiliza, além de sua memória pessoal, a memória histórica da região baseada em pesquisas feitas pessoalmente ou a partir de testemunhos de amigos e parentes, sobre fatos e pessoas que viveram em Belém durante a primeira metade do século XX. Essa memória pessoal e a memória histórica da região amazônica vão dialogar nos romances de Jurandir, transformando-os em "lugares de memória". Se sairmos um pouco do campo da história para o da sociologia, dialogando com Maurice Halbwachs, perceberemos que a memória coletiva tende a influir, através de um processo pendular, na memória individual:

Para que nossa memória se auxilie com a dos outros, não basta que eles nos tragam seus depoimentos: é necessário ainda que ela não tenha cessado ainda de concordar com suas memórias e que haja bastante ponto de contato entre uma e as outras para que a lembrança que nos recordam possa ser reconstruída sobre um fundamento comum (HALBwACHs, 2013, p.22).

Dalcídio Jurandir, ao escrever seus romances, elide através dos emaranhados de sua escrita, a memória coletiva dos sujeitos amazônicos, priorizando os mais pobres, demarcada por experiências e testemunhos individuais, que ganham no leitor a mesma força de identificação e significados. Assim, a escrita do autor significa, em síntese, uma memória da Amazônia atravessada por diversas memórias individuais.

Segundo Pierre Nora (1993), na contemporaneidade, não habitamos mais a nossa memória, logo temos uma grande necessidade de lhe consagrar lugares específicos. Porém, esses lugares da memória pertencem ao domínio não só da mesma,

3 Considerar o acervo do autor que está sob a guarda do projeto Memorial do Livro Moronguetá, ligado ao Fórum Landi, coordenado pelo professor Flávio Nassar e ligado à Faculdade de Arquitetura e Urbanismo da UFPA. Ali percebemos o cuidado de Jurandir ao elaborar reportagens ou romances; seu processo de escritura é antecedido de pesquisas de campo, como demonstrará um dos anexos deste ensaio, relacionados à Mãe Ciana, personagem de Belém do Grão-Pará. 
mas também da história, o que faz com que esses lugares da memória contemporâneos postulem outra história. Os lugares da memória seriam, ao mesmo tempo, materiais, simbólicos e funcionais, e só poderiam existir se tivessem "vontade da memória", condição primeira e que não pode ser abandonada, caso contrário, todo "objeto digno de lembrança se transformaria em um lugar de memória" (NoRA, 1993, p. 22). Posteriormente, haveria um jogo dialético entre memória e história, com a interação de ambas.

Dessa forma, seguindo o proposto por Nora, uma obra de arte, como os textos literários de Dalcídio Jurandir, teria a "vontade de memória", já que seria um testemunho "voluntariamente produzido para ser reproduzido como tal" (NorA, 1993, p. 22). Entre a "memória verdadeira" do romancista (definida por Nora como "afetiva e mágica") e a "memória alçada pela história" (NoRA, 1993, p. 9), ou seja, a memória histórica da região amazônica (que seria a representação do passado a partir do discurso crítico, segundo aquele historiador) haveria um jogo dialético, interativo e recíproco. Deste jogo surgiria o "Ciclo do Extremo Norte" como um lugar de memória sobre a Amazônia, e em especial sobre a cidade de Belém, do Marajó e do Baixo Amazonas paraense.

Com uma pesquisa de caráter transdisciplinar, a historiadora Jacy Alves de Seixas (2004) envolve a literatura de Proust e a filosofia de Bergson, Bachelard e Nietzche para repensar as relações entre memória e história, e, mais do que isso, para propor um diálogo que possibilite informar a história sobre os procedimentos próprios da memória (nem sempre redutíveis aos métodos historiográficos). Seixas discorda de Nora, quando este afirma que "se ainda habitássemos a nossa memória não haveria a necessidade de lhe consagrar lugares específicos" (NoRA, 1993). Tal discordância surge do fato do autor desconsiderar um traço fundamental da memória, a "espacialização do tempo" (SEIXAs, 2004, p. 44), traço este que nos é fundamental, para compreender a perspectiva política de Dalcídio Jurandir, que apontará para uma percepção bastante singular sobre o "fausto" e a decadência da cidade de Belém, percepção distanciada do modo saudosista como as elites remontam o passado da belle époque amazônica. Dalcídio é crítico. Ele sugere, através do emprego da ironia, que a decadência é mais sentida pelas elites, na medida em que as classes populares foram, em grande parte, excluídas das benesses daquele "fausto".

A memória exprime-se, materializa-se e atualiza-se a partir dos "lugares de memória", como nos romances que compõem o "Ciclo do Extremo Norte". Dessa forma, os lugares da memória não representariam, como afirma Nora, a manifestação de uma memória historicizada, mas sim a "irrupção afetiva e simbólica da memória em seu diálogo sempre atual com a história” (SEIXAS, 2004, p. 44). É porque Dalcídio Jurandir ainda habita a sua memória, no momento em que escreve o "Ciclo do Extremo Norte", a partir de uma perspectiva que romances podem ser compreendidos como "lugares de memória". O fato dessa memória ser descontínua e fragmentada, como ocorre nas experiências da modernidade, não 
caracteriza uma ausência de memória, mas, ao contrário, uma escrita de memória bastante singularizada.

A perspectiva de Seixas vai ao encontro do nosso propósito de análise, uma vez que a historiadora trabalha a memória no plural, ou seja, não se ocupando apenas com a "memória voluntária", mas também com a "memória involuntária", afirmando inclusive que ambas existem nos romances do século XX, como nos de Marcel Proust. É a partir da obra de Proust que a pesquisadora envereda por uma discussão sobre memória voluntária e involuntária. Se o historiador se ocupa apenas com a memória voluntária, afirma Seixas, o mesmo deixará escapar toda a dimensão afetiva e descontínua da vida e das ações humanas.

Essa faceta involuntária da memória dialoga com diversos e múltiplos tempos, reatualizando as experiências passadas. Essas reutilizações ocorrem em um "instante", que não possui duração maior do que "um relâmpago", e é por esse motivo que a materialidade da memória nos aparece como algo que "irrompe", um passado que retorna, porque de alguma forma ainda não passou, continua ativo e atual, sendo então retomado, recriado, reatualizado (SEIXAS, 2004, p. 49).

Dalcídio Jurandir afirmou, em vários momentos, que buscou "fragmentos de sua memória" para construir a narrativa do "Ciclo do Extremo Norte", a partir "do menino que foi, com os pés fincados em Cachoeira do Arari" e olhando Belém sempre como "casa alheia", pintando os seus romances com cores de um testemunho histórico de um caboclo marajoara (SEIXAS, 2004, p. 96-97). Sua memória múltipla (voluntária e involuntária) vai dialogar com diversos tempos e espaços os anos de 1900 em Cachoeira do Arari; a Amazônia cabana de meados do século XIX; a Belém da população pobre da virada do século XIX para o XX; a Belém da belle époque lemista do "fausto" e do progresso urbano; a Belém da decadência dos anos de 1920; o tempo da sua vivência de funcionário público e romancista no interior do Pará e na capital da Amazônia nos anos de 1930 e 1940. Ele reatualiza as suas experiências passadas, que irrompem recriadas em seus romances do Ciclo, lugares da memória do extremo Norte do Brasil. Como em Proust, a memória em Dalcídio Jurandir opera em fusão, recuperando a superposição de tempos múltiplos, justamente porque incorpora o instante e coloca-o na condição de memória. Isto pode ser visto no emprego do discurso indireto livre e dos monólogos que marcam as enunciações do romance dalcidiano. O exemplo mais apropriado que bem corporifica esse exercício de fixação de memória se dá através da manipulação que faz Alfredo (o protagonista da grande maioria dos romances amazônicos do autor) do caroço de tucumã, ${ }^{4}$ espécie de 'válvula de escape' desse personagem diante das angústias a que ele se submete na trama das narrativas.

É Marcel Proust que, segundo Seixas (2004), ao fundir instante e duração, cria esteticamente uma dimensão particular do tempo, que seria "atemporal", algo que só emerge porque adentra todos os tempos descontínuos e assimétricos constitu-

\footnotetext{
4 O tucumã é uma palmeira amazônica que tem o nome cientifico de Astrocaryum aculeatum.
} 
tivos de uma duração. Essa dimensão atemporal tanto pode ser verificada nos sonhos e devaneios de Alfredo, quanto na representação que faz o narrador de fatos históricos, como Cabanagem, Belle époque de Antônio Lemos, decadência do fausto etc. É este atemporal proustiano que irrompe nas tramas do Ciclo do Extremo Norte, porque tramam todos os tempos descontínuos e assimétricos constitutivos da duração proposta por Dalcídio Jurandir.

A memória em Dalcídio Jurandir é, portanto, construtiva. Ela age tecendo fios entre narrador, personagens, tempo/espaço e acontecimentos, o que torna alguns personagens mais densos do que os outros. Dalcídio Jurandir, tal qual Proust, reencontra o vivido ao mesmo tempo no passado e no presente e desta maneira recria a sua percepção do real. De uma realidade que se forma na memória e que encontra o seu lugar na trama de sua narrativa. $O$ tempo que ele retoma, seja a Cabanagem, a Belle époque ou a decadência econômica do látex, é um tempo que começa de novo e não se refere apenas ao passado e ao presente, mas projeto, para além do tempo da narrativa, de um futuro promissor.

Através de manobras enunciativas - uso de monólogo e discurso indireto livre -, a memória atualiza o passado ao introduzi-lo no presente, porém, esse passado não é único, ele é plural, o que Seixas (2004) chama de "plural de descontinuidades". Os lugares da memória acoplam-se formando mundos à parte e que são passíveis de serem colocados em comunicação pela memória. Essa memória pode nos levar a lugares diversos - e a narrativa dos romances de Dalcídio Jurandir sobre Belém é um bom exemplo disso -, "viajando" pelos vários tempos e lugares, pelas "cidades" de Belém (Covões de São Brás, Nazaré, Umarizal, etc.). Esses planos descontínuos e lacunares da memória constroem uma continuidade, algo que é único. Por isso a autora afirma que a memória "constrói o real muito mais do que o resgata" (SEIXAS, 2004, p. 51).

Podemos inferir uma possibilidade de construção do real em Dalcídio Jurandir, a partir de uma passagem do romance Belém do Grão-Pará, na qual o narrador, ao descrever o Círio de Nazaré (vivido pelas personagens pobres da trama), apropriase desta faceta involuntária da memória do escritor, dialogando com tempos diversos e múltiplos. Trata-se da passagem em que a personagem "mãe Ciana" vê a procissão da transladação chegar à Igreja da Sé, no bairro da Cidade Velha, em Belém. A procissão ocorre na noite anterior ao Círio de Nazaré, uma das maiores festas religiosas do Brasil. Todos esses tempos vistos por uma personagem como mãe Ciana ou que recebem a adesão do narrador de Belém do Grão-Pará se reatualizam neste instante de fé e devoção, que irrompe exatamente na chegada da imagem de Nossa Senhora de Nazaré à Igreja da Sé, retornando todo um passado que continua ativo e atual, ressignificado pelo narrador instruído por Dalcídio Jurandir:

A transladação chegou ao ponto, na Sé, agora escoava-se. A Sé guarda a imagem. Cobria-se de visões do seu passado, a Cidade Velha. Mãe Ciana via o tempo velho chegando. Nasciam de novo, prateando sobre o arvorecer antigo, aqueles igarapés em que índio andou, cabano viu. Ao pé 
do Castelo, as idosas gurijubas rabeavam. Desembarcavam pagés do salgado, seus cachimbos acesos, os maracás, suas rezas. Das velhas barcas de Portugal pulavam as marujadas. E negros do Mazagão com seus tambores, dentro da Sé, a modo que estrondavam. Mãe Ciana trazia também seus pretos do Araquiçaua, os afogados e desaparecidos tirava do fundo e do invisível, todos eles na Sé, guardando a imagem, falando suas tantas reclamações, seus ais. E os do Guamá, também não? O sono da Cobra Norato debaixo da Sé, a Mãe Ciana escutava (JuRANDir, 2004, p. 284).

Então, ao incorporar o "instante" da chegada da procissão na Igreja da Sé, colocando-o na condição de memória, o narrador, industriado pelo autor diegético, opera uma fusão, recuperando a superposição dos múltiplos tempos, momento em que as ruas de Belém eram rios, onde os índios andavam em seus barcos, tempo em que o cabano revolucionário viveu, em que pajés vinham do Salgado para a transladação, em que barcas de Portugal traziam marujas, em que negros escravos tocavam seus tambores dentro da Sé, tempo em que muitas "mães Cianas", miseráveis e invisíveis, levavam suas dores para suplicar por salvação. Todos esses tempos se superpõem, ao serem fundidos, instante e duração, o instante da transladação e a duração dos múltiplos tempos de Belém do Grão-Pará, sendo assim é criada, esteticamente, uma dimensão múltipla e transtemporal, que emerge a partir do momento em que se tramaram vários tempos descontínuos e assimétricos.

Ao reencontrar o vivido no tempo passado de indígenas, cabanos, marujos, negros escravos, caboclos, pajés, e no tempo, presente da trama, Jurandir recria a sua percepção do real, de uma realidade que funde vários tempos e lugares e que se forma em sua memória, encontrando o seu lugar na narrativa. O tempo da transladação de 1922 é um tempo que começa de novo e que se refere não apenas ao passado e ao presente, mas também à possibilidade de um futuro diferente, aberto pela rebelião dos roceiros do interior do Pará. Desta forma, o romance Belém do Grão-Pará, e todo o Ciclo do Extremo Norte, pode ser compreendido como um lugar de memória da região.

\section{Mãe Ciana e a 'Aristocracia do Pés no Chão'}

Mãe Ciana é personagem que, embora aparentemente ocupe espaço secundário na trama do romance Belém do Grão-Pará, constitui uma alegoria da diversidade etnocultural da Amazônia, fruto envolvente da mistura entre nativos ameríndios e negros, 'filhos' das diáspora africana no Norte do Brasil.

Ciana é fundamental para que Alfredo se reconheça como negro e assim recupere o elo afetivo com sua mãe, dona Amélia; Ciana constitui uma espécie de ponte de ligação entre Alfredo, o alter ego de Dalcídio Jurandir, e os problemas sociais da periferia de Belém como a rebelião dos roceiros no Guamá, movimento este que se sobrepunha, paulatinamente, na trama, à Belém dos escombros lemistas, de atritos sociais entre classes antagônicas. A escrita desse romance tinha um 
compromisso com a maioria ${ }^{5}$ explorada. Um romance político que seria a sua contribuição decisiva para a transformação do mundo. Era, desta feita, preciso mostrar para os oprimidos a possibilidade da "desagregação das coisas", através da escrita da história "a contrapelo". (BENJAMIN, 2012, p. 13).

O narrador nos relata que mãe Ciana vivia durante o tempo da Belém do fausto "na Bernaldo Couto, olhando o muro lateral da Santa Casa". Bem diferente dos palacetes de mármore e granito importados da Europa, mãe Ciana morava numa barraca, "beiral de palha, como uma pestana, sobre a única janelita envergonhada" (JuRANDIR, 2004, p. 185). Nesses tempos vivia com a personagem Seu Lício, mas a história de ambos é mais antiga, não datando o narrador, mas deixando com que os rastros nos façam inferir que por volta do final do XIX e início do XX os dois já estivessem juntos.

Mãe Ciana é definida pelo narrador como uma mulher de uma dedicação apaixonada. Mais cafuza que preta, com roupa sempre limpa, não tinha medo de pegar no pesado, e quando enviuvou do primeiro marido, amassou e vendeu açaí na Domingos Marreiros, com a bandeira na porta, faxinou muita casa de branco, vendeu tacacá, e, nos idos de 1922, fazia "cheiro de papelinho para freguesia certa, certas casas da Independência, Rui Barbosa e Reduto" (JuRANDIR, 2004, p. 184).

$\mathrm{O}$ vai e vem desta labuta, as inúmeras atividades nas quais as mulheres como Mãe Ciana se envolviam, nos sugere a dura luta pela sobrevivência das mulheres das classes populares do final do século XIX e início do século XX. As mulheres tinham pouca possibilidade de empregos regulares, uma vez que raras eram as que trabalhavam como balconistas no comércio de alguma loja (DIAS, 1995), sobrando para elas o comércio mais pobre, a venda de gêneros alimentícios. É possível inferir também que muitas destas mulheres eram mal-vistas neste momento em Belém, uma vez que o seu lugar social não era as ruas, mais o lar, cuidando da casa e da prole (LEAL, 2008).

Mãe Ciana, a personagem que não apanhava o bonde, que rodava a cidade entregando seus cheiros a pé, fazia desta uma de suas mais marcantes características, como que, implicitamente, o autor quisesse mostrar o brio da aristocracia da qual ele próprio descendia, "a aristocracia do pé no chão": a pé a personagem procurava os parentes no Ver-o-Peso, a pé foi madrinha de muitas crianças, de batismo e de fogueira, a pé ficou conhecida e conheceu os pajés, frequentava de vez em quando o terreiro de Dr. Luís França na Cremação, conheceu de feitiçaria, de encantos e de ervas maravilhosas. Mas sua sina era estar sempre em busca de Seu Lício pela cidade, com os dois pés fincados no chão, na sua realidade de trabalho duro. O narrador afirma que, embora devota da virgem de Nazaré, acompanhando

\footnotetext{
5 Uma das fortes preocupações dos intelectuais que militavam na Academia do Peixe Frito era inverter a dinâmica e o fluxo de poder; antes as áreas centrais da cidade eram vistas com primazia nas representações literárias. A ação dos acadêmicos do Peixe Frito faz inverter e deixa as periferias da cidade como centros do teatrum mundi. Isto está muito bem representado na literatura de autores como Bruno de Menezes e Dalcidio Jurandir, por exemplo.
} 
todos os anos a transladação, era com Nossa Senhora do Rosário que mãe Ciana se pegava de fato, ela e "a pretada inteira" se pegavam com a imagem da santa, na Igreja construída pelos escravos (JURANDIR, 2004, p. 472).

Por meio das memórias da personagem Seu Lício, companheiro de mãe Ciana, vamos tecendo o lugar das classes populares no "fausto" da Belém do Grão-Pará, de Dalcídio Jurandir. A personagem, seu Lício narra que viu Mãe Ciana pela primeira vez em um carimbó, ${ }^{6}$ no Pinheiro. Voltava ele de Mosqueiro, da Baía do Sol, depois de vários dias de "vadiação" pelos "terreiros e chãos de festa, velório e serenata" (JuRANDIR, 2004, p. 398). Mãe Ciana, muito cheirosa, estava de "chinelinho no pé, bata branca, pente alto na cabeça e dançava como ninguém ao som do carimbó" (JURANDIR, 2004, p. 398).

Mas é o caminho do carimbó à casa de Mãe Ciana que nos chama atenção. As personagens populares da trama de Dalcídio Jurandir não passaram por nenhum dos símbolos do progresso burguês. Havia o poço, de onde a população tirava sua água que não era encanada, havia lama e não ruas pavimentadas, havia palhoças e não palacetes, haviam mulheres trabalhando na peneira da tapioca para fazer beijus, e não banquetes europeus e nem mulheres tocando piano. Narrando o período longo em que tentava convencer mãe Ciana a aceitá-lo, Seu Lício nos mostra o quanto a vida desta mulher era feita de "labutas das casas desses brancos, trabalhar no tacacá", mas também no cheiro, na banca do peixe, na mercearia. $\mathrm{Na}$ festa de Nazaré, "longe dos luxos e do muito caro das barracas e das diversões do Largo", estava, enfim, mãe Ciana trabalhando como mingauzeira no "cu da festa, que era atrás do arraial, aquele arraialzinho da maior pobreza" (JURANDIR, 2004, p. 399). O modo como o narrador "adere" à Mãe Ciana nos faz admirá-la e devotar a ela a mais intensa simpatia. Ciana é uma digna representante da 'nata' da "aristocracia dos pés no chão", que ele tão bem representou.

Para Dalcídio Jurandir, essa "aristocracia do pé no chão" era o que de melhor existia no romance Belém do Grão-Pará. Independente dos tempos, era ela que fazia pulsar a cidade a partir das ruas, dos cheiros, das danças, da música, das comidas, das feiras, da arte, do brio, da dedicação, da honestidade, da determinação, da força, da inteligência. É esta gente de pé no chão, muito bem representada por Dalcídio Jurandir, que contradiz a ideia equivocada das elites de que, após a derrocada do látex no mercado internacional, a capital do Pará vive a mais sombria decadência. Como já dissemos, o povo da periferia foi, em grande parte, excluído do fausto da Belle Époque. Mãe Ciana, Libânia, Isaura, Antônio e tantos outros, estavam envolvidos com as tarefas inglórias de um cotidiano duro, servindo aos brancos, lutando pela sobrevivência, embora isso não signifique que eles fossem desesperançados.

\footnotetext{
6 Ritmo musical amazônico, patrimônio cultural brasileiro e, também, um gênero de dança de roda de origem indígena típica da região Norte brasileira, praticado no Pará a partir do século XVII; influenciado por negros (percussão e sensualidade) e portugueses (palmas e sopro). O nome é oriundo de um instrumento musical, um tambor artesanal chamado "curimbó".
} 
Ao pensarmos, panoramicamente, na atividade intelectual de Dalcídio Jurandir - o jornalista, o romancista, o poeta bissexto, o militante, o internacionalista - enfim, o homem de ideias, chegaremos à síntese de que a função do intelectual materialista era a de libertar o presente do passado que o oprimia, para salvá-lo de uma história oficial, na qual existia a empatia apenas com o vencedor. A história de Belém, representada por Dalcídio Jurandir, demonstrará que ele tem, como não poderia deixar de ser, empatia com as classes populares, que conheciam a realidade cotidiana de opressão e de luta. Os sujeitos da periferia que protagonizaram os romances do Extremo Norte resistem e se dedicam à busca de um bem maior: em que o sol nasça igualmente para todos. Mãe Ciana, Magá, Alfredo, Seu Lício, Libânia, enfim, todos estão afinados para resistir; ele compõe como que uma orquestra em que o 'regente' é o narrador do romance, mas o maestro é mesmo Dalcídio Jurandir e sua escrita singular que problematizou a Amazônia e seus sujeitos como ninguém, dedicando-se a uma causa que aponta para a libertação de toda a opressão.

\section{Referências}

Benjamin, Walter. Sobre o conceito da História. IN: BARREto, João. Walter Benjamin: o anjo da história. Belo Horizonte: autêntica, 2012.

DiAs, Maria Odila Leite da Silva. Quotidiano e poder em São Paulo do século XIX. São Paulo: brasiliense, 1995 .

Halbwachs, Maurice. A memória coletiva. Tradução de Beatriz Sidou. 2 ed. São Paulo: Centauro, 2013.

Jurandir, Dalcídio. Belém do Grão-Pará. 2 ed. . Belém/Rio de Janeiro: Edufpa/Casa de Rui Barbosa, 2004.

LeAl, Luiz Augusto Pinheiro. A Política da Capoeiragem: história social da capoeira e do boi bumbá no Pará Republicano (1888- 1906). Salvador: EDUFBA, 2008.

NorA, Pierre. Entre Memória e História: problemática dos lugares. IN: Projeto História, São Paulo, n.10, dez.1993.

Nunes, Benedito; Pereira, Ruy; Pereira, Soraia Reolon. Dalcídio Jurandir - Romancista da Amazônia. Literatura e Memória. Belém: SECULT - FCRB - IDJ, 2006.

Nunes, Paulo; Torres, Vânia. 'Negritude e protagonismo: um peixefritano modo de ser e estar no olho do furação'. Revista eletrônica Asas da Palavra, abril, 2018. Disponível em: http://revistas.unam.br/index.php/asasdapalavra/article. Acesso em março de 2019.

Seixas, Jacy Alves de. Percursos de Memória em terras de História: problemáticas atuais. IN: Bresciani, Stella; NAXARA, Mércia (orgs.). Memória e (res)sentimento: indagações sobre uma questão sensível. Campinas-SP: editora da UNICAMP, 2004 . 
Recebido em 11 de setembro de 2019.

Aprovado em 17 de setembro de 2020.

\section{Resumo}

\section{Narrativa e memória na Amazônia de Dalcídio Jurandir}

\section{Paulo Jorge Nunes, Maíra Oliveira Maia e Thainá Oliveira Chemelo}

Este texto enfatiza a escrita do romance amazônico de Dalcídio Jurandir e reforça a ideia de uma memória à moda, principalmente de Maurice Hawbachs. Trata-se de uma análise dos romances Belém do Grão-Pará (1960) e Passagem dos Inocentes (1963), através dos quais Dalcídio Jurandir representa a sociedade paraense da primeira metade do século XX, a partir de uma experiência testemunhal, vista das periferias da grande cidade da Amazônia oriental. Para demonstrar essa preocupação do autor em retratar "as minorias", nos debruçamos sobre a análise da personagem "Mãe Ciana", de Belém do Grão-Pará, que, aparentemente secundária, constitui uma perfeita alegoria étnicocultural da Amazônia. Ressaltamos que o autor utiliza, além de sua memória pessoal, a memória histórica da região, baseado em pesquisas feitas na Belém da primeira metade do século XX, transformando seus livros em "lugares de memória", emaranhados aos coletivos dos sujeitos amazônicos, priorizando os mais pobres, por ele denominados "aristocracia do pé no chão". $\mathrm{O}$ autor de Chove nos campos de Cachoeira percebia a história como um campo de lutas, sua narrativa está comprometida com a maioria explorada, daí porque seus escritos configuram manifestos que apontam para a transformação da sociedade. 